Three days later I was called again. The ablominal pains had grown worse, especially on the lower left side, and radiated down the left thigh. She had frequent soft stools and the rumbling of gas was marked. Temperature was $100 \mathrm{~F}$.; pulse, 124. Peristaltic waves could he seen over the lower left abdomen, where there was also tenderness and more resistance than on the right side. The hernial mass was a little larger, was tender, and was ne longer reducible. Operation was now most urgently advised, but absolutely refused. During the day, the temperature rose to $102.6 \mathrm{~F}$. and an indistinet mass could be felt in the lower left quadrant of the abdomen. On the evoning of the next day, the bowels moved, but with much difliculty and straining. There was considerable resistance in the lower left side of the abdomen and the entire abdomen was moderately swollen and tympanitic, especially over the course of the colon. The patient felt nauseated and vomited a little bile. The hernial mass was tense, tender, and flat to percussion. Temperature was $102.2 \mathrm{~F}$; pulse, 124. Operation was now insisted on. The patient was taken to the German Deaconess Hospital at once, where I operated that same evening.

Operation.-An incision was made over the supposed hernial swelling and large enough to do a radical operation for the cure of femoral hernia. Imagine my surprise on dissecting out the mass to find that it did not emanate from the saphen. ous opening at all, but was continuous on either end with the internal saphenous vein just below its emergence from the saplienous opening. It formed a sacculated pouch springing from the anterior wall of the vein. The vein was tied off above and below the tumor and the latter removed. On opening, it was found to contain a fairly fresh unorganized blood-clot and the wall of the pouch was a dilatation of the wall of the vein. There was no hernial sac visible, neither was the femoral ring abnormally large; nevertheless I sutured Poupart's ligament to the pectineal fascin with one catgut stitch, thus preventing the possibility of a future hernin or the recurrence of one that might have slipped back into the abdomen. The wound was closed with interrupted silkworm-gut sutures. Examination under anesthesia now revealed a large infiltrating mass occupying the pouch of Douglas and extending upward into the left side of the abdomen. I decided to terminate the operation at this point and await developments.

Subsequent History.-The patient ran an jrregular temperature ranging from 00 to $103 \mathrm{~F}$. for ten days, after which it suddenly came to normal, where it stayed during the remaining eight days that she was in the hospital. During this time, the pelvic nass became gradually smaller and on her discharge could barely be felt. As it gave no symptoms and seemed to be gradually disappearing, the paticnt was tentatively discharged from the hospital.

In looking over the literature, I find a saphenous varix in this location a vary rare oceurence. I could find no case reported in the last three years. Although varicosities are common enough in the long saphenous vein, they are uncommon in this situation. According to MacCready's statistics quoted in von Bergman's and Keen's text-books on surgery, a saphenous varix was mistaken for femoral hernia nine times as against fortyseven times that abscess and one bundred and fifteen times that enlarged lymphatic glands were the cause of a mistaken diagnosis.

So much for a simple varix. But to find such a tumor, with impulse on coughing and casily reducible, after three days no longer reducible and tender in a patient with rising temperature, abdominal cramps, swollen tympanitic abdomen, and the other symptoms I have meutioned, was an unusual coincidence.

The explanation was simple enough after the operation. The varix had become thrombosed during the three days and the temperature and abdorninal symptoms were due to the pelvic exudate.

519 East Utica Street.

\section{A SIMPLE APPARATUS FOR ACCTRATELY FIXING BLOOD-SLIDES BY HEAT}

\author{
GEORGE B. LAWSON, A.M., M.D. \\ ROANOKE, VA.
}

In fixing blood-slides by heat, one finds that the results of the copperplate method are so inconstant that it is difficult to get a good specimen unless one keeps in constant practice. 'There is no way of determining. the exact amount of heat used or of keeping the heat resular. I have devised the following simple apparatus for office and laboratory use :

As slown in the illustration, an ordinary laboratory stand ard supports an iron dish, C, resting on an asbestos plate, under which is a gas burner. This iron dish is easily made by screwing a two-inch nipple into a pipe cap. This dish is filled with petrolatum, into which is sunk a small, thin copper cuip so that the end sticks out as shown at B. This cup is

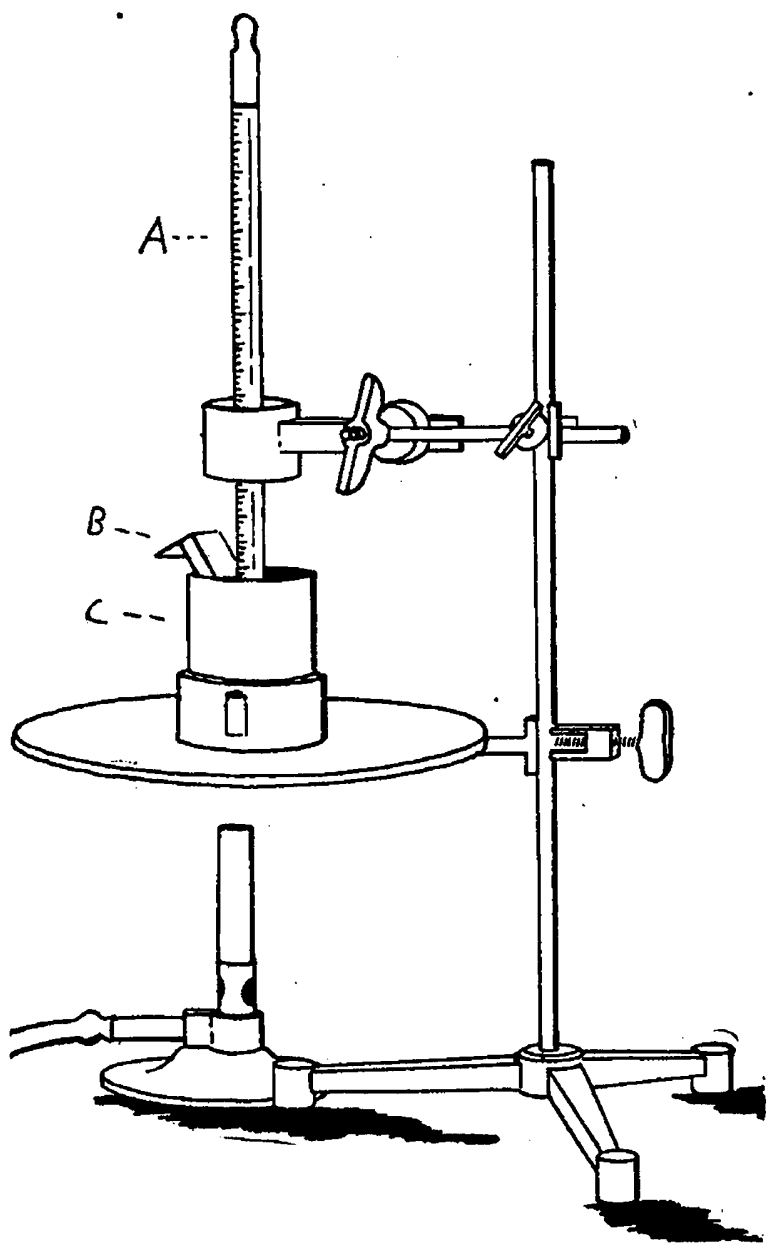

Apparatus for fixing blood-slides by hent. A, thermometer for melstering amount of heat; $B$, copper cup por holding blood-sllde $C$, dish containlng petrolatum in which cup with blood-slide is Immersed.

just large enough to admit with ease the glass slide. In the petrolatum is sunk the bulb of a thermometer, $A$. The exact temperature is registered by the thermometer. The slide may be introduced by using a small copper strip bent at an angle at the ends; and when the blood is sufficiently heated the slide and copper strip are withdrawn. With Ehrlich's stain I have obtained the best results by henting to $280 \mathrm{~F}$. for seven minutes.

'The disadvantages of this apparatus are that it requires constant attention. The advantages are that the slide may be accurately heated, and this may be done by one's untrained office assistant, whereas by the copperplate method one can hardly get constantly good results no matter how well one is trained. 